\title{
Copolímeros de Estireno-Divinilbenzeno Impregnados com Agentes Complexantes Organofosforados para Separação de Terras Raras.
}

\author{
Celina C. R. Barbosa, J osé Waldemar S.D. Cunha, Viviane G. Teixeira, Fernanda M.B. Coutinho
}

Resumo: Copolímeros de estireno-divinilbenzeno para aplicação em cromatografia de extração foram sintetizados em presença de agentes complexantes seletivos para terras raras, o fosfato monoácido de bis(2-etil-hexila), DEHPA e o 2-etil-hexil fosfonato monoácido de 2-etil-hexila, EHEHPA. Os copolímeros foram preparados através de polimerização em suspensão utilizando como diluentes os agentes complexantes puros ou combinados com o solvente tolueno (TOL). A influência das condições de síntese, tais como: a razão agente complexante/ TOL; o grau de diluição dos monômeros e o teor de divinilbenzeno, na estrutura porosa dos copolímeros foi investigada através de suas características físicas tais como densidade aparente, volume de poros fixos, área específica e através de microscopia ótica e eletrônica de varredura. Os copolímeros foram avaliados em relação ao processo de separação de terras raras. Assim foram determinadas a capacidade total e a cinética de complexação em relação ao íon gadolínio. O teor de agente complexante impregnado em cada suporte foi função da quantidade do agente complexante nas misturas. Foi otimizada a quantidade máxima do agente complexante que pode ser utilizada na síntese, de modo a obter suportes com alta capacidade de complexação, sem o comprometimento de sua resistência mecânica. A capacidade total de complexação variou com a quantidade de agente complexante impregnado no suporte e a cinética de complexação variou principalmente com o diâmetro médio de poros, pois este determina a velocidade de difusão dos íons no suporte.

Palavras-chave: Copolímeros de estireno-divinilbenzeno, macroporosidade, cromatografia de extração de terras raras.

\section{Introdução}

No processo de cromatografia de extração, íons de metais pesados em soluções ácidas podem ser concentrados ou separados pela ação de agentes complexantes imobilizados em suportes inertes. Esse processo vem sendo bastante estudado na separação de íons de terras raras (TR), pois combina a seletividade da extração por formação de complexos com a eficiência da separação cromatográfica. ${ }^{[1]}$

Os copolímeros de estireno (Sty) e divinilbenzeno (DVB) são os materiais mais utilizados como suporte para cromatografia de extração, devido à facilidade de se controlar sua morfologia externa (distribuição de tamanho de partícula em faixas determinadas) e interna (porosidade e área específica em uma larga faixa $)^{[2]}$.

Celina C. R. Barbosa, José Waldemar S.D. Cunha, Instituto de Engenharia Nuclear, Comissão Nacional de Energia Nuclear, Viviane G. Teixeira, Fernanda M.B. Coutinho, Instituto de Macromoléculas Professora Eloisa Mano, Universidade Federal do Rio de Janeiro, C. P. 68.525, Rio de Janeiro, CEP: 21945-970, RJ. 
Como esses polímeros são usualmente empregados na forma de pérolas, o processo de síntese mais utilizado é a polimerização em suspensão. Inicialmente, os monômeros, o iniciador e uma mistura de diluentes formam uma única fase, que fica dispersa na forma de gotas esféricas em meio aquoso. Durante a polimerização ocorre uma separação de fases, originando uma fase rica em polímero e outra rica em diluente. O polímero precipita na forma de esferas, separando-se como um aglomerado de microesferas (núcleos). Em seguida ocorre a ligação das microesferas pela polimerização dos monômeros residuais que as solvatam. A estrutura morfológica formada depende do diluente utilizado, se o diluente apresentar afinidade termodinâmica pelo copolímero, na etapa de separação de fases, as cadeias poliméricas e os núcleos se tornam menos emaranhados e, consequentemente, as microsferas mais solvatadas se apresentam menos compactadas, originando um número maior de poros de tamanho pequeno. Com a diminuição do poder solvatante do diluente (não-solvatante), na etapa de separação de fases, as cadeias se tornam menos inchadas e mais emaranhadas originando microesferas mais compactas, aumentando o espaço entre os aglomerados de microsferas (os macroporos) e o tamanho das microesferas ${ }^{[2-4]}$.

Os agentes complexantes podem ser impregnados na estrutura polimérica por dois métodos: por inchamento do polímero pronto ou durante a reação de polimerização. A impregnação dos suportes póssíntese apresenta limitações devido ao carreamento do complexante durante a retenção e eluição dos íons e também à dificuldade de se obter uma razão ótima entre o agente complexante e o suporte. $\mathrm{O}$ grau de impregnação ótimo corresponde a uma quantidade mínima necessária para cobrir toda a superfície do suporte como um filme líquido homogêneo ${ }^{[5]}$.

A melhor forma de minimizar esses problemas é através da impregnação do suporte polimérico durante sua síntese. Neste caso o agente complexante funciona como um diluente inerte não-solvatante durante a reação de polimerização, exercendo grande influência na morfologia e propriedades do suporte.

Kroebel e Meyer, da Bayer AG ${ }^{[6]}$, em 1971 foram os primeiros pesquisadores a preparar suportes à base de Sty-DVB impregnados com agentes complexantes durante a síntese. Essas resinas são conhecidas comercialmente como Resinas Levextrel e são impregnadas com fosfato de tributila (TBP), fosfato mono ácido de di(2-etil-hexila) (DEHPA) e o ácido di (2,4,4trimetilpentil) fosfínico.

Vários agentes complexantes têm sido utilizados na impregnação de suportes para a cromatografia de extração, os mais utilizados são os organofosforados. DEHPA tem sido um dos agentes complexantes mais empregados devido ao alto fator de separação para um par de TR (terras raras) adjacentes. Atualmente o EHEHPA (2-etil-hexil fosfonato ácido de 2-etilhexila) vem substituindo o DEHPA na separação das TR mais pesadas, devido ao maior fator de separação que este complexante apresenta para esses íons ${ }^{[1]}$.

O objetivo deste trabalho foi correlacionar a estrutura porosa e o grau de impregnação de suportes Sty-DVB, sintetizados na presença de complexantes organofosforados, com as propriedades de retenção de íons de terras raras.

\section{Parte experimental}

\section{Preparação dos Suportes}

Os copolímeros Sty-DVB foram obtidos através de polimerização em suspensão na presença dos agentes complexantes DEHPA ou EHEHPA puros ou combinados com tolueno (TOL) ${ }^{[7-8]}$. Foram estudados 4 sistemas variando-se o teor de DVB em $30 \%$ e em $60 \%$ e o grau de diluição em $100 \%$ e em $200 \%$. Para cada sistema foi investigada a influência da razão tolueno/ agente complexante e do tipo de agente complexante sobre as propriedades dos copolímeros.

\section{Caracterização dos Suportes}

Os efeitos do grau de diluição dos monômeros, grau de reticulação e da razão DEHPA/TOL e EHEHPA/TOL foram avaliados através de determinação da área específica, densidade aparente, volume de poros através de medidas de retenção de água e observações por microscopia ótica e eletrônica de varredura ${ }^{[8]}$.

\section{Avaliação dos suportes}

\section{a) Determinação do teor de agente complexante nos suportes:}

Os agentes complexantes possuem em sua estrutura um hidrogênio ácido, que pode ser quantificado através da titulação ácido-base ${ }^{[8]}$. 
b) Determinação da capacidade total de retenção dos suportes:

Para essas determinações foi utilizada solução padrão de gadolínio III a $25 \mathrm{~g} / \mathrm{L}$. Cerca de $5 \mathrm{ml}$ de cada suporte é colocado sob agitação com $15 \mathrm{ml}$ de solução padrão de $\mathrm{Gd}^{+3}$ e $10 \mathrm{ml}$ de tampão glicina $(\mathrm{pH}=$ 2,60 ). Após uma hora, o suporte foi separado da solução por filtração, neutralizado e seco em estufa até peso constante. O filtrado foi titulado com EDTA na presença de alaranjado de xilenol. A capacidade de retenção por massa do suporte foi calculada pela diferença entre o número de moles de íons gadolínio III adicionados e o número de moles que restaram no filtrado ${ }^{[8]}$.

\section{c) Determinação da cinética de retenção de íons $G d^{+3}$ nos suportes:}

A determinação da cinética de adsorção dos íons $\mathrm{Gd}^{+3}$ nos suportes foi conduzida utilizando um excesso de resina (agente complexante) em relação ao íon. A quantidade de íons $\mathrm{Gd}^{+3}$ utilizada foi cerca de $10 \%$ da capacidade total média dos suportes. Para essa determinação foram testados 2 métodos. No primeiro método, em um erlenmayer, aproximadamente $1 \mathrm{~g}$ do suporte foi agitado com $20 \mathrm{ml}$ de solução padrão de íons $\mathrm{Gd}^{+3}(4 \mathrm{~g} / \mathrm{L})$ durante os períodos de contato fixados em 1, 2, 5, 10 e 15, 30 e 60 minutos. Ao final de cada período de contato os suportes foram filtrados sob pressão reduzida e a concentração de gadolínio no filtrado foi determinada pela mesma técnica já descrita anteriormente ${ }^{[7]}$. No segundo método o suporte foi colocado em contato com a solução de íons gadolínio em um erlenmayer provido de um tubo de vidro com uma malha fina em uma das extremidades, que permitia a retirada de alíquotas da solução sem a presença do copolímero. Através desse tubo de vidro foram recolhidas alíquotas de 1,00 $\mathrm{ml}$ nos tempos determinados para o contato ${ }^{[8]}$. O decréscimo da concentração de gadolínio em cada alíquota foi determinado por titulação com solução de EDTA. Os dois métodos testados apresentaram concordância nos resultados.

\section{Resultados e Discussão}

Estudo do comportamento de misturas dos agentes complexantes com tolueno em relação à formação da estrutura porosa dos copolímeros

Tanto DEHPA como EHEHPA tem duas funções distintas no sistema: durante a síntese atuam como
Tabela 1. Características físicas dos copolímeros sintetizados em presença de misturas TOL/DEHPA e TOL/EHEHPA com 30\% de DVB e $100 \%$ de diluição

\begin{tabular}{|c|c|c|c|}
\hline Composição & $\begin{array}{c}\text { da } \\
\left(\mathrm{g} / \mathrm{cm}^{3}\right)\end{array}$ & $\begin{array}{c}\mathbf{V p} \\
\left(\left(\mathrm{cm}^{3}\right) / \mathbf{g}\right)\end{array}$ & $\begin{array}{c}\mathbf{S} \\
\left(\mathrm{m}^{2} / \mathrm{g}\right)\end{array}$ \\
\hline $100 \%$ TOL & 0,62 & 0 & 0 \\
\hline $\begin{array}{l}80 \% \text { TOL } \\
20 \% \text { DEHPA }\end{array}$ & 0,61 & 0 & 0 \\
\hline $\begin{array}{l}60 \% \text { TOL } \\
40 \% \text { DEHPA }\end{array}$ & 0,51 & 0,12 & 78 \\
\hline $\begin{array}{l}50 \% \text { TOL } \\
50 \% \text { DEHPA }\end{array}$ & 0,45 & 0,30 & 113 \\
\hline $\begin{array}{l}20 \% \text { TOL } \\
80 \% \text { DEHPA }\end{array}$ & 0,31 & 0,48 & 75 \\
\hline $100 \%$ DEHPA & 0,27 & 0,55 & 26 \\
\hline $\begin{array}{l}80 \% \text { TOL } \\
20 \% \text { EHEHPA }\end{array}$ & 0,61 & 0 & 0 \\
\hline $\begin{array}{l}60 \% \text { TOL } \\
40 \% \text { EHEHPA }\end{array}$ & 0,54 & 0,15 & 49 \\
\hline $\begin{array}{l}50 \% \text { TOL } \\
50 \% \text { EHEHPA }\end{array}$ & 0,37 & 0,60 & 114 \\
\hline $\begin{array}{l}20 \% \text { TOL } \\
80 \% \text { EHEHPA }\end{array}$ & 0,31 & 0,94 & 76 \\
\hline $100 \%$ EHEHPA & 0,26 & 1,19 & 43 \\
\hline
\end{tabular}

* Tamanho médio de partícula $=100 \mu \mathrm{m}$

$\mathrm{da}=$ densidade aparente $; \mathrm{Vp}=$ volume de poros; $\mathrm{S}=$ área específica

agentes formadores de poros e após a síntese como agentes complexantes. O tolueno foi escolhido por ser um bom solvente para os agentes complexantes e por apresentar afinidade termodinâmica pelo copolímero, favorecendo assim a melhor distribuição do agente complexante na estrutura polimérica.

A Tabela 1 mostra as características físicas dos copolímeros Sty-DVB sintetizados na presença de misturas TOL/DEHPA e TOL/EHEHPA com 30\% de DVB e $100 \%$ de diluição (sistema 1).

Os copolímeros formados em presença dessas misturas apresentaram características intermediárias às produzidas pelos copolímeros sintetizados com os diluentes puros. De uma maneira geral, o aumento do teor dos componentes não solvatantes provocou uma diminuição do poder solvatante das misturas diluentes, produzindo estruturas macroporosas.

Neste sistema a mudança do DEHPA para EHEHPA originou a formação de estruturas mais porosas, que resultou no aumento do volume de poros (Tabela 1). O aumento da macroporosidade pode ser observado através de micrografias de microscopia 


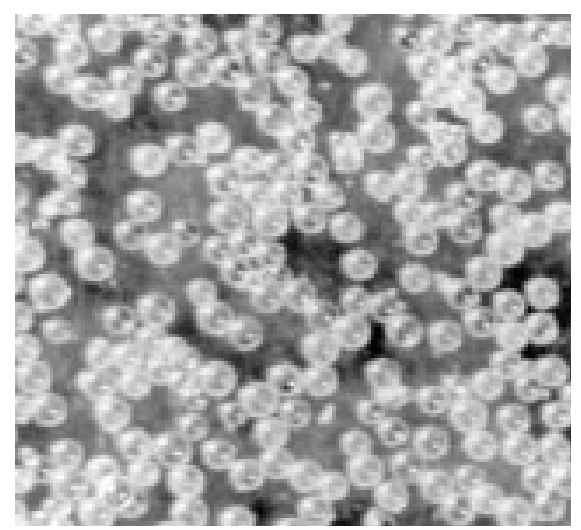

(a)

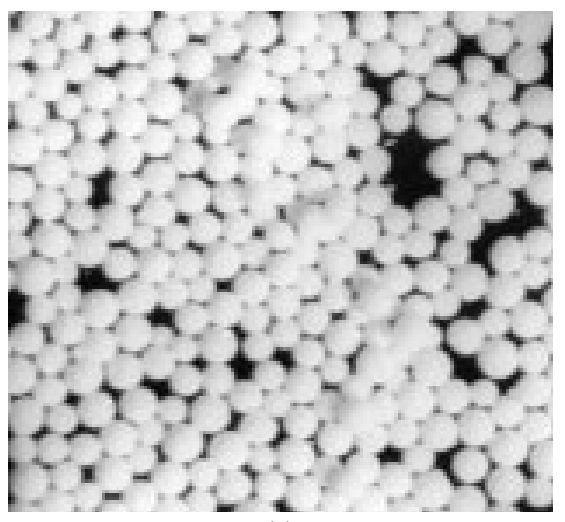

(c)

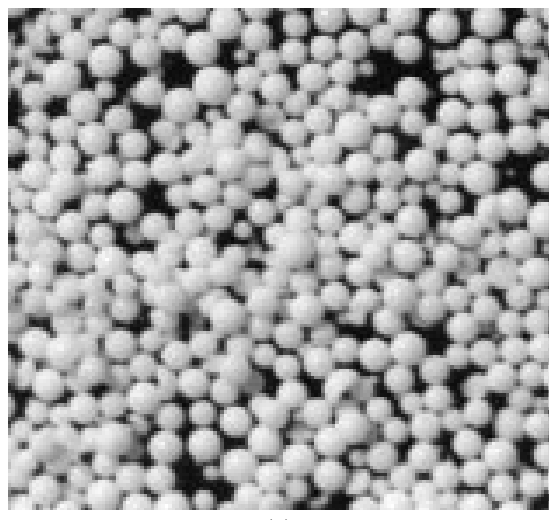

(e)

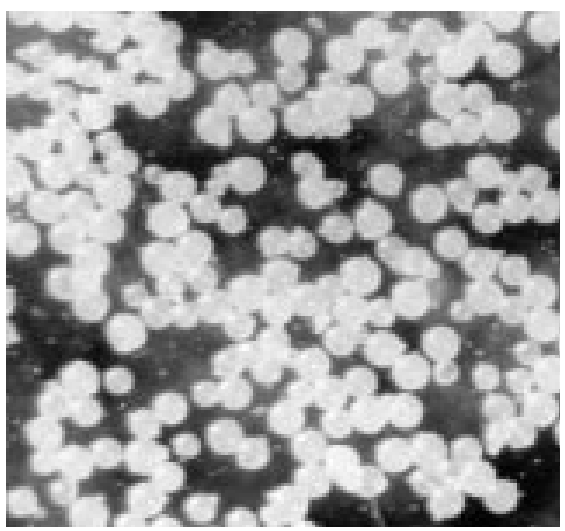

(b)

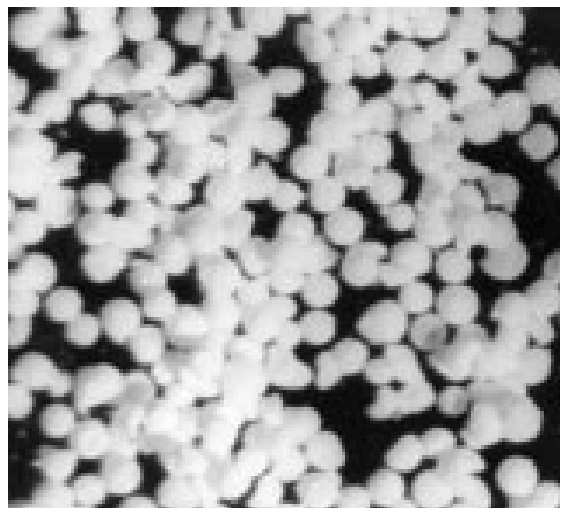

(d)

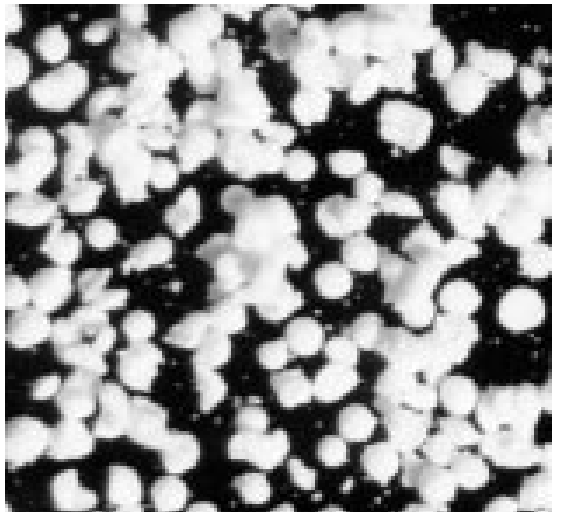

(f)

Figura 1. Micrografias de microscopia ótica dos copolímeros sintetizados com misturas TOL/DEHPA no sistema 1: a) 80/20; b) 60/40; c) 20/80; d) 0/100, e no sistema 4: e) 50/50; f) 20/80.

ótica (Figura 1). A diminuição do poder solvatante da mistura leva à formação de estruturas mais heterogêneas, onde ocorre maior refração da luz quando esta passa pelo interior das pérolas, resultando no aumento da opacidade das pérolas.

Os valores de área específica para os copolímeros obtidos nesses dois sistemas foram independentes do diluente não solvatante utilizado. Os copolímeros apresentaram pequenas variações em uma faixa de valores baixa, não sendo suficiente, talvez, para promover a distribuição homogênea do agente complexante sobre a matriz polimérica.
O aumento do grau de diluição para $200 \%$, mantendo o teor de DVB em 30\% (sistema 2), provocou aumento da porosidade em todas as composições em comparação com o sistema 1 (Tabela 2). Este efeito foi mais pronunciado nos suportes sintetizados com a mistura tolueno/EHEHPA. Isso indica que EHEHPA tem uma influência mais marcante sobre o poder solvatante do tolueno do que o DEHPA. Geralmente, o aumento do grau de diluição acarreta em um aumento do volume de poros, porém a extensão desse efeito depende da afinidade do diluente pelo copolímero. Quanto maior o poder solvatante do diluente, menor 
Tabela 2. Características físicas dos copolímeros sintetizados em presença de misturas TOL/DEHPA e TOL/EHEHPA com 30\% de DVB e $200 \%$ de diluição

\begin{tabular}{lccc}
\hline \multicolumn{1}{c}{ Composição } & $\begin{array}{c}\mathbf{d a} \\
\left(\mathbf{g} / \mathbf{c m}^{3}\right)\end{array}$ & $\begin{array}{c}\mathbf{V p} \\
\left(\mathbf{c m}^{3} / \mathbf{g}\right)\end{array}$ & $\begin{array}{c}\mathbf{S} \\
\left(\mathbf{m}^{2} / \mathbf{g}\right)\end{array}$ \\
\hline $\begin{array}{l}\text { 60\% TOL } \\
\text { 40\% DEHPA }\end{array}$ & 0,40 & 0,51 & 85 \\
$\begin{array}{l}\text { 50\% TOL } \\
\text { 50\% DEHPA }\end{array}$ & 0,33 & 0,69 & 87 \\
60\% TOL & 0,36 & 0,75 & 140 \\
$40 \%$ EHEHPA & & & \\
$50 \%$ TOL & 0,28 & 1,10 & 144 \\
$50 \%$ EHEHPA & & & \\
\hline
\end{tabular}

será o efeito do grau de diluição sobre a porosidade ${ }^{[9]}$.

A área específica dos copolímeros apresentou grande variação ao se comparar os sistemas com DEHPA e EHEHPA (Tabela 2). O aumento mais pronunciado dos valores de área específica dos copolímeros sintetizados com as misturas tolueno/EHEHPA se deve ao aumento da quantidade de poros pequenos, sem alteração do diâmetro médio de poros. Isto indica que a mistura TOL/EHEHPA tem características mais solvatantes que a mistura TOL/DEHPA.

No sistema com $60 \%$ de DVB e $100 \%$ de diluição (sistema 3), o aumento do teor de DVB em relação ao sistema 1 (Tabelas 1 e 3), para as misturas mais solvatantes, $60 \%$ de tolueno/40\% de agente complexante, provocou aumento da porosidade dos copolímeros. Isto pode ser observado pela comparação dos valores de densidade aparente, volume de poros e área específica dos copolímeros produzidos com

Tabela 3. Características físicas dos copolímeros sintetizados em presença de misturas TOL/DEHPA e TOL/EHEHPA com 60\% de DVB e $100 \%$ de diluição

\begin{tabular}{lccc}
\hline \multicolumn{1}{c}{ Composição } & $\begin{array}{c}\text { da } \\
\left(\mathbf{g} / \mathbf{c m}^{3}\right)\end{array}$ & $\begin{array}{c}\mathbf{V p} \\
\left(\left(\mathbf{c m}^{3}\right) / \mathbf{g}\right)\end{array}$ & $\begin{array}{c}\mathbf{S} \\
\left(\mathbf{m}^{2} / \mathbf{g}\right)\end{array}$ \\
\hline $\begin{array}{l}\text { 60\% TOL } \\
40 \% \text { DEHPA }\end{array}$ & 0,36 & 0,33 & 99 \\
$\begin{array}{l}\text { 50\% TOL } \\
50 \% \text { DEHPA }\end{array}$ & 0,34 & 0,34 & 125 \\
20\% TOL & 0,30 & 0,48 & 77 \\
$80 \%$ DEHPA & & & \\
60\% TOL & 0,41 & 0,54 & 142 \\
$40 \%$ EHEHPA & & & \\
50\% TOL & 0,38 & 0,59 & 132 \\
$50 \%$ EHEHPA & & & 75 \\
20\% TOL & 0,29 & 0,93 & \\
$80 \%$ EHEHPA & & & \\
\hline
\end{tabular}

Tabela 4. Características físicas dos copolímeros sintetizados em presença de misturas TOL/DEHPA e TOL/EHEHPA com 60\% de DVB e $200 \%$ de diluição

\begin{tabular}{lccc}
\hline \multicolumn{1}{c}{ Composição } & $\begin{array}{c}\mathbf{d a} \\
\left(\mathbf{g} / \mathbf{c m}^{3}\right)\end{array}$ & $\begin{array}{c}\mathbf{V p} \\
\left(\mathbf{c m}^{3} / \mathbf{g}\right)\end{array}$ & $\begin{array}{c}\mathbf{S} \\
\left(\mathbf{m}^{2} / \mathbf{g}\right)\end{array}$ \\
\hline $\begin{array}{l}\text { 60\% TOL } \\
40 \% \text { DEHPA }\end{array}$ & 0,32 & 0,48 & 150 \\
$\begin{array}{l}50 \% \text { TOL } \\
50 \% \text { DEHPA }\end{array}$ & 0,27 & 0,70 & 145 \\
60\% TOL & 0,39 & 0,57 & 127 \\
$40 \%$ EHEHPA & & & \\
$50 \%$ TOL & 0,27 & 1,00 & 127 \\
$50 \%$ EHEHPA & & & \\
\hline
\end{tabular}

este sistema quando comparado com o sistema 1. Porém, para as misturas menos solvatantes $(50 \%$ e $20 \%$ de tolueno), o aumento do teor de DVB não provocou modificações acentuadas. Isto mostra que a quantidade de DVB utilizada nas reações do sistema 1 já era suficiente para causar uma grande separação de fases durante a formação do copolímero, pois o meio já era favorável à precipitação.

As diferenças da superfície interna dos copolímeros pode ser observada através das micrografias de microscopia eletrônica de varredura (Figura 2 ). No interior das pérolas a estrutura polimérica é constituída de aglomerados não muito compactados. Com o aumento do teor de EHEHPA nas misturas, observa-se um aumento das microesferas e de seus aglomerados.

A combinação do aumento do teor de DVB e do grau de diluição (60\% de DVB e $200 \%$ de diluição) (sistema 4), deu origem a formação de copolímeros com diferentes tipos de estruturas porosas (Tabela 4). O aumento da diluição provocou mudanças mais acentuadas nos valores de área específica e volume de poros do que o aumento do grau de reticulação. Isto mostra que a diluição tem um efeito mais significativo na formação da estrutura porosa do que o teor de DVB.

Neste sistema as misturas tolueno/DEHPA produziram copolímeros com menores valores de volume de poros e maiores valores de área específica quando comparados com os obtidos com o sistema 2 (Tabelas $2 \mathrm{e} 4$ ). Isto pode ser devido à maior estabilidade de poros com diâmetro médio pequeno, em função do aumento de DVB que contribui para o aumento da área específica.

Influência das composições das misturas sobre 0 teor de agente complexante impregnado no suporte

Para uma dada composição da mistura diluente, 


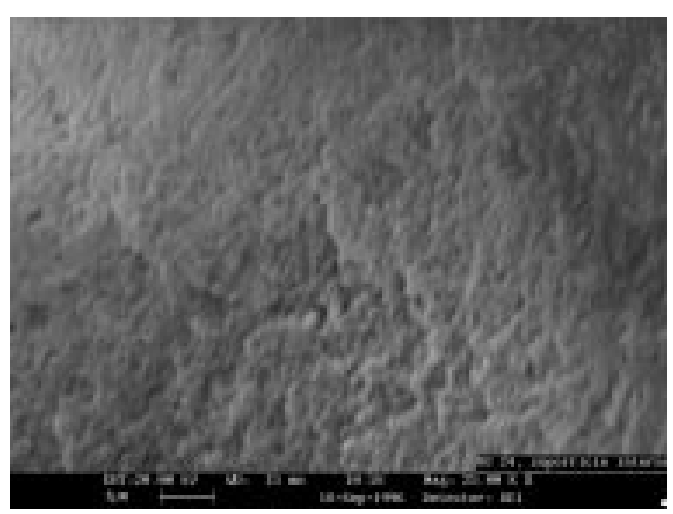

(a)

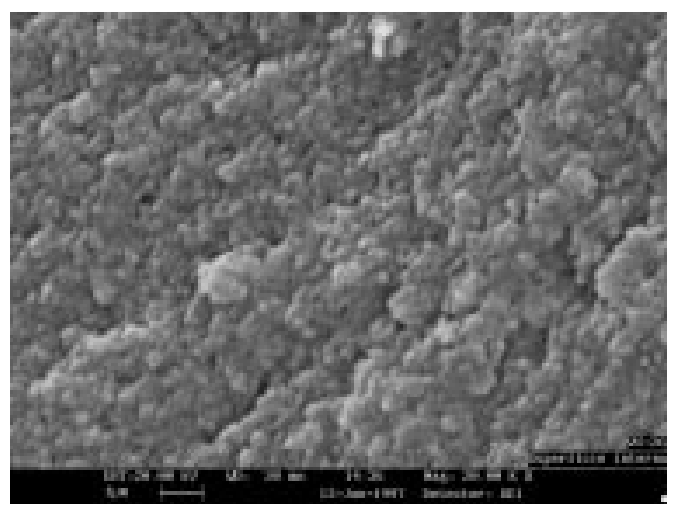

(c)

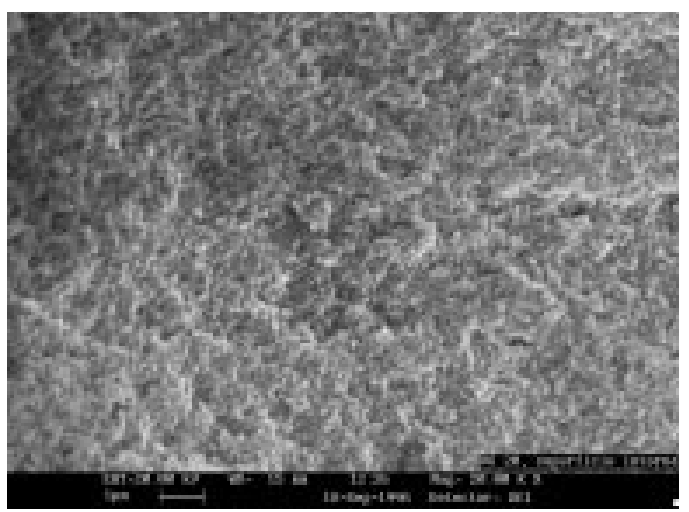

(b)

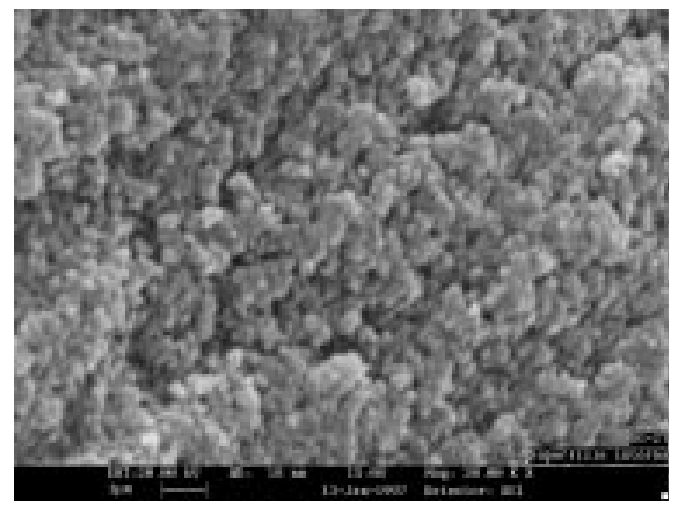

(d)

Figura 2. Micrografias de microscopia eletrônica de varredura dos copolímeros sintetizados com misturas TOL/EHEPA no sistema 1: a) 60/40; b) 50/50; e no sistema $3:$ c) 60/40; d) 50/50.

os copolímeros sintetizados com os dois agentes complexantes apresentaram graus de impregnação próximos (Tabelas 5 a 8). Para os copolímeros sintetizados com a mistura $60 \%$ de tolueno/40\% de EHEHPA, o aumento do grau de diluição de $100 \%$ para $200 \%$, mantendo o teor de DVB constante em $60 \%$, não provocou mudanças significativas nos valores de volume de poros (Tabelas 3 e 4), porém produziu um grande aumento do teor de EHEHPA impregnado no copolímero. Isto se deve ao maior volume de mistura diluente e, consequentemente, maior quantidade de EHEHPA em relação à quantidade de monômeros (Tabelas 7 e 8).

Para uma dada composição, independente do agente complexante utilizado, o aumento do teor de DVB para $60 \%$, mantendo a diluição em $100 \%$, provocou aumento no volume de poros e na área específica dos copolímeros (Tabelas 1 e 3). Porém o teor de agente complexante não sofreu variação considerável (Tabela 5 e 7 ).

O teor de agente complexante impregnado no suporte independe, portanto, do tipo de agente utilizado na mistura e do tipo de estrutura formada, sendo função apenas da quantidade de agente complexante utilizada inicialmente na mistura diluente.
Estudo do efeito da morfologia dos suportes sobre a capacidade de retenção de terras raras

Além do grau de impregnação do agente complexante, a estrutura porosa do suporte é outro fator de grande importância para o desempenho na retenção de íons. A existência de macroporos facilita a permeação dos íons pela matriz polimérica, aumentando a velocidade de complexação, enquanto que altas áreas específicas são desejáveis para a melhor distribuição do agente complexante no suporte.

A capacidade total de complexação dos suportes impregnados foi determinada utilizando-se um excesso de aproximadamente $200 \%$ de íons $\mathrm{Gd}^{+3} \mathrm{em}$ relação a quantidade do agente complexante contido na massa do suporte utilizada no ensaio. O excesso foi calculado utilizando-se a razão estequiométrica estabelecida para formação do complexo ( 3 moles de agente complexante: $1 \mathrm{~mol} \mathrm{de} \mathrm{Gd}^{+3}$ ).

Além do excesso de íons gadolínio em relação ao agente complexante, o pH da solução exerce um grande efeito sobre o equilíbrio da reação de complexação. A alta concentração de íons hidrogênio reverte o equilíbrio da reação para a forma ácida do agente complexante, diminuindo a capacidade do suporte. 
Tabela 5. Grau de impregnação e capacidade total de complexação dos suportes sintetizados em presença de misturas TOL/DEHPA e TOL/EHEHPA com $30 \%$ de DVB e $100 \%$ de diluição

\begin{tabular}{|c|c|c|c|c|}
\hline Composição & $\begin{array}{c}\text { Teor de agente } \\
\text { complexante } \\
(\%)\end{array}$ & $\begin{array}{c}\text { C } \\
(\mathrm{gGd} / \mathrm{g} \text { suporte })\end{array}$ & $\begin{array}{c}\text { C teórica } \\
(\mathrm{gGd} / \mathrm{g} \text { suporte })\end{array}$ & $\begin{array}{c}\text { Desvio } \\
(\%)\end{array}$ \\
\hline $\begin{array}{l}80 \% \text { tolueno } \\
20 \% \text { DEHPA }\end{array}$ & 18 & 0 & 0,029 & - \\
\hline $\begin{array}{l}60 \% \text { tolueno } \\
40 \% \text { DEHPA }\end{array}$ & 28 & 0,005 & 0,045 & 88 \\
\hline $\begin{array}{l}50 \% \text { tolueno } \\
50 \% \text { DEHPA }\end{array}$ & 32 & 0,012 & 0,052 & 77 \\
\hline $\begin{array}{l}20 \% \text { tolueno } \\
80 \% \text { DEHPA }\end{array}$ & 40 & 0,028 & 0,066 & 57 \\
\hline $100 \%$ DEHPA & 45 & 0,044 & 0,073 & 40 \\
\hline $\begin{array}{l}80 \% \text { tolueno } \\
20 \% \text { EHEHPA }\end{array}$ & 17 & 0 & 0,029 & - \\
\hline $\begin{array}{l}60 \% \text { tolueno } \\
40 \% \text { EHEHPA }\end{array}$ & 26 & 0,008 & 0,044 & 82 \\
\hline $\begin{array}{l}50 \% \text { tolueno } \\
50 \% \text { EHEHPA }\end{array}$ & 33 & 0,025 & 0,056 & 55 \\
\hline $\begin{array}{l}20 \% \text { tolueno } \\
80 \% \text { EHEHPA }\end{array}$ & 43 & 0,048 & 0,074 & 35 \\
\hline $100 \%$ EHEHPA & 52 & 0,053 & 0,089 & 40 \\
\hline
\end{tabular}

Assim, torna-se necessário o uso de um tampão para consumir os íons $\mathrm{H}^{+}$gerados, de forma que estes não mascarem a capacidade real do suporte. Foi então utilizado um tampão de ácido monocloroacético e ácido aminoacético. O uso de excesso de íons gadolínio e de tampão, garante o favorecimento do equilíbrio para a formação do complexo. Assim, pode-se assegurar que a diferença entre as capacidades de retenção dos copolímeros será função apenas do teor de agente complexante e da morfologia do suporte.
Nas Tabelas 5, 6, 7 e 8 são apresentados o grau de impregnação dos suportes, as capacidades experimental e teórica (calculados em função do teor de agente complexante no copolímero), assim como o desvio apresentado pela capacidade experimental em relação à teórica.

A capacidade dos suportes sintetizados com os dois agentes complexantes apresentaram comportamento semelhante em relação ao aumento do teor de DEHPA ou EHEHPA na mistura diluente.

Tabela 6. Grau de impregnação e capacidade total de complexação dos suportes sintetizados em presença de misturas TOL/DEHPA e TOL/EHEHPA com $30 \%$ de DVB e $200 \%$ de diluição

\begin{tabular}{|c|c|c|c|c|}
\hline Composição & $\begin{array}{c}\text { Teor de agente } \\
\text { complexante } \\
(\%)\end{array}$ & $\begin{array}{c}\mathrm{C} \\
(\mathrm{gGd} / \mathrm{g} \text { suporte })\end{array}$ & $\begin{array}{c}\text { C teórica } \\
\text { (gGd/g suporte) }\end{array}$ & $\begin{array}{c}\text { Desvio } \\
(\%)\end{array}$ \\
\hline $\begin{array}{l}60 \% \text { TOL } \\
40 \% \text { DEHPA }\end{array}$ & 45 & 0,039 & 0,070 & 44 \\
\hline $\begin{array}{l}50 \% \text { TOL } \\
50 \% \text { DEHPA }\end{array}$ & 49 & 0,045 & 0,080 & 43 \\
\hline $\begin{array}{l}60 \% \text { TOL } \\
40 \% \text { EHEHPA }\end{array}$ & 44 & 0,034 & 0,074 & 54 \\
\hline $\begin{array}{l}50 \% \text { TOL } \\
50 \% \text { EHEHPA }\end{array}$ & 52 & 0,041 & 0,088 & 53 \\
\hline
\end{tabular}


Tabela 7. Grau de impregnação e capacidade total de complexação dos suportes sintetizados em presença de misturas TOL/DEHPA e TOL/ EHEHPA com $60 \%$ de DVB e $100 \%$ de diluição

\begin{tabular}{|c|c|c|c|c|}
\hline Composição & $\begin{array}{c}\text { Teor de agente } \\
\text { complexante } \\
(\%)\end{array}$ & $\begin{array}{c}\text { C } \\
(\mathrm{gGd} / \mathrm{g} \text { suporte) }\end{array}$ & $\begin{array}{c}\text { C teórica } \\
\text { (gGd/g suporte) }\end{array}$ & $\begin{array}{c}\text { Desvio } \\
(\%)\end{array}$ \\
\hline $\begin{array}{l}60 \% \text { tolueno } \\
40 \% \text { DEHPA }\end{array}$ & 26 & 0,020 & 0,042 & 38 \\
\hline $\begin{array}{l}50 \% \text { tolueno } \\
50 \% \text { DEHPA }\end{array}$ & 32 & 0,037 & 0,052 & 29 \\
\hline $\begin{array}{l}20 \% \text { tolueno } \\
80 \% \text { DEHPA }\end{array}$ & 45 & 0,051 & 0,073 & 30 \\
\hline $\begin{array}{l}60 \% \text { tolueno } \\
40 \% \text { EHEHPA }\end{array}$ & 26 & 0,025 & 0,044 & 43 \\
\hline $\begin{array}{l}50 \% \text { tolueno } \\
50 \% \text { EHEHPA }\end{array}$ & 30 & 0,044 & 0,050 & 12 \\
\hline $\begin{array}{l}20 \% \text { tolueno } \\
80 \% \text { EHEHPA }\end{array}$ & 43 & 0,058 & 0,072 & 19 \\
\hline
\end{tabular}

De maneira geral, o desvio do comportamento experimental e teórico aumentou com o acréscimo do teor de tolueno. Nas composições com alto teor de tolueno há formação preferencial de estruturas do tipo gel ou com baixa porosidade, sendo assim as soluções aquosas não conseguem ter acesso ao agente complexante contido no interior das pérolas, distribuído entre as cadeias poliméricas. Entretanto, durante a extração do agente complexante com etanol para a sua quantificação, ocorre o inchamento do copolímero pelo etanol, que promove a extração do agente complexante presente na parte gel do suporte. Dessa forma, a diferença entre o agente complexante acessível ao etanol e à água se torna muito grande, aumentando o desvio entre as capacidades experimental e teórica.

Comparando-se as composições do sistema 1 para os dois agentes complexantes, observa-se uma dimi- nuição do desvio entre as capacidades experimental e teórica para o sistema EHEHPA/TOL. Isto se deve principalmente ao maior volume de poros dos suportes sintetizados na presença deste agente complexante (Tabelas 1 e 5).

No sistema 2 (30\% de DVB e $200 \%$ de diluição), o aumento do volume de poros para a mistura $50 \%$ TOL/50\%EHEHPA parece não ter sido suficiente para promover uma boa distribuição do alto teor de EHEHPA no suporte. Devido à má distribuição do agente complexante, a capacidade deste suporte foi praticamente a mesma que a do suporte sintetizado com a mistura 50\% TOL/50\%EHEHPA no sistema 3, que contém menor teor do agente complexante (Tabelas 6 e 7).

Independente do tipo de agente complexante utilizado, os suportes sintetizados no sistema 3 apresentaram praticamente os mesmos valores de

Tabela 8. Grau de impregnação e capacidade total de complexação dos suportes sintetizados em presença de misturas TOL/DEHPA e TOL/ EHEHPA com $60 \%$ de DVB e $200 \%$ de diluição

\begin{tabular}{lcccc}
\hline \multicolumn{1}{c}{ Composição } & $\begin{array}{c}\text { Teor de agente } \\
\text { complexante } \\
(\%)\end{array}$ & $\begin{array}{c}\mathbf{C} \\
\text { (gGd/g suporte) }\end{array}$ & $\begin{array}{c}\mathbf{C} \text { teórica } \\
\text { (gGd/g suporte) }\end{array}$ & $\begin{array}{c}\text { Desvio } \\
(\%)\end{array}$ \\
\hline $\begin{array}{l}\text { 60\% tolueno } \\
40 \% \text { DEHPA }\end{array}$ & 44 & 0,039 & 0,072 & 46 \\
$50 \%$ tolueno & 50 & 0,040 & 0,081 & 50 \\
$50 \%$ DEHPA & 44 & 0,038 & 0,075 & 49 \\
$60 \%$ tolueno & & & \\
$40 \%$ EHEHPA & & 0,066 & 0,086 & 23 \\
$50 \%$ tolueno & 50 & & & \\
$50 \%$ EHEHPA & & & & \\
\hline
\end{tabular}


capacidade (Tabela 7). Observa-se também neste sistema que os suportes sintetizados com as misturas $60 \%$ TOL/40\%EHEHPA e $50 \%$ TOL $/ 50 \%$ EHEHPA possuem os mesmos valores de área específica e volume de poros, no entanto o copolímero sintetizado com $50 \%$ de tolueno apresentou um menor desvio da capacidade. Este resultado pode ser atribuído ao aumento do diâmetro médio de poros (Figura 2).

O comportamento dos suportes sintetizados no sistema 4 (60\% de DVB e $200 \%$ de diluição), com misturas TOL/EHEHPA foi semelhante ao dos suportes sintetizados com as mesmas composições no sistema 2 (Tabelas 6 e 8). Porém comparando-se as características dos dois sistemas, percebe-se um aumento do volume de poros para os suportes sintetizados no sistema 2 (Tabela 2 e 4). Aparentemente, o aumento do volume de poros para estes suportes favoreceu a melhor distribuição da mesma quantidade de EHEHPA, que resultou em um menor desvio da capacidade.

Portanto, parece haver uma dependência entre o teor de agente complexante e a capacidade dos suportes. Suportes preparados com DEHPA ou EHEHPA devem ser sintetizados em condições que produzam um aumento no volume de poros, para favorecer a melhor distribuição do agente complexante.

Estudo do efeito da morfologia dos suportes sobre a cinética de retenção de terras raras

O comportamento cinético dos suportes pode ser determinado através de medidas da quantidade de íons retidos em função do tempo. Utiliza-se um excesso de agente complexante em relação ao íon, para que a reação não seja muito rápida a ponto de não se perceber o decréscimo da concentração do íon com o tempo. A velocidade de retenção de íons nos suportes depende da quantidade e distribuição do agente complexante no copolímero bem como de sua estrutura porosa.

Os diagramas que relacionam o decréscimo da concentração de íons em função do tempo, têm como ordenada a relação $\mathrm{C} / \mathrm{Co}$, ou seja, a razão entre a concentração de íons no tempo t e a concentração inicial.

Os copolímeros preparados com 30\% de DVB e $100 \%$ de diluição (sistema 1 ) em presença de misturas com $50 \% \mathrm{TOL} / 50 \%$ agente complexante apresen-

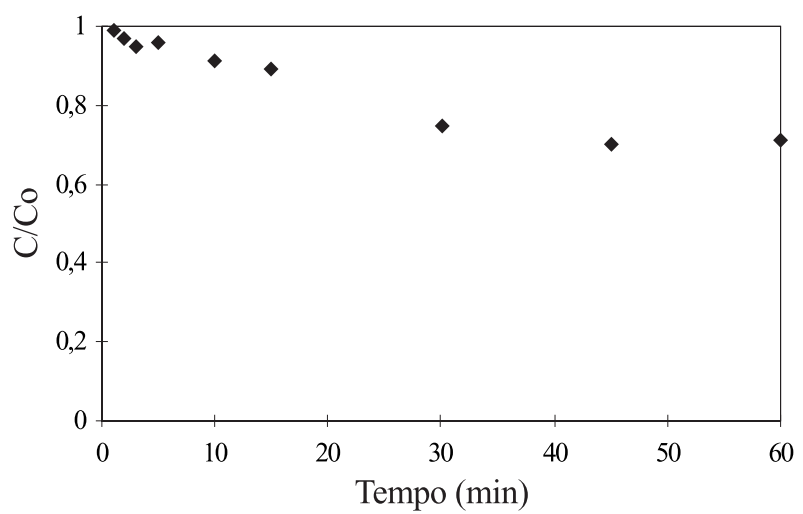

(a)

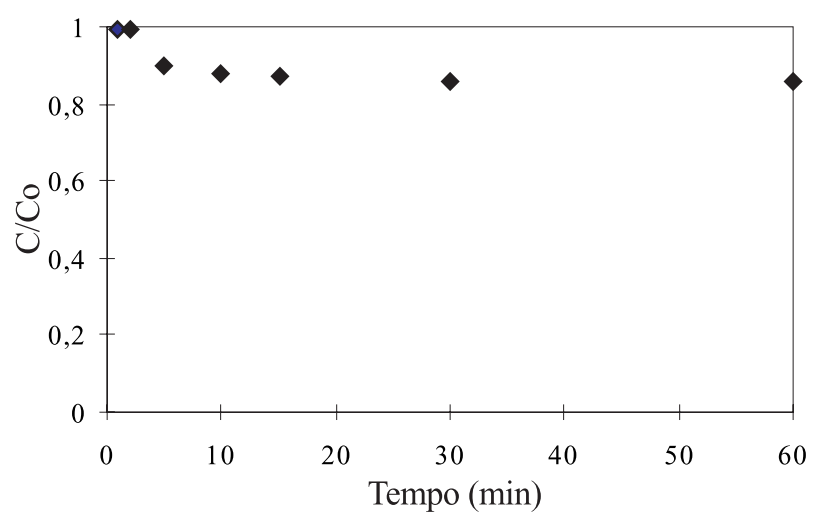

(b)

Figura 3. Comportamento cinético dos copolímeros de Sty-DVB sintetizados em presença de misturas (a) 50\% EHEHPA/50\% TOL e (b) 50\% DEHPA/50\% TOL no sistema 1 (30\% de DVB, 100\% de diluição)

taram velocidade de retenção diferentes. O suporte preparado com EHEHPA apresentou maior velocidade de retenção do que o preparado com DEHPA (Figura 3). Isto é devido a diferenças na porosidade dos suportes. O suporte sintetizado com EHEHPA apresentou valores mais altos de volume de poros e o mesmo valor de área específica que o copolímero preparado com DEHPA. Neste caso o aumento do volume de poros favorece o aumento do diâmetro médio de poros (D), já que os valores de área específica são iguais.

Para os suportes preparados no sistema 3 (30\% de DVB e $200 \%$ de diluição) com as misturas 60\% TOL/40\%DEHPA e 50\%TOL/50\% DEHPA, o aumento do teor de DEHPA aumentou a capacidade de retenção de íons. Porém, o suporte sintetizado com $40 \%$ de DEHPA atingiu o equilíbrio mais rapidamente. O decréscimo da velocidade de retenção para a mistura com 50\% de DEHPA indica que altos graus de diluição com altos teores de agente complexante reduzem a velocidade de retenção, provavelmente devido à obstrução de poros provocada pelo excesso 


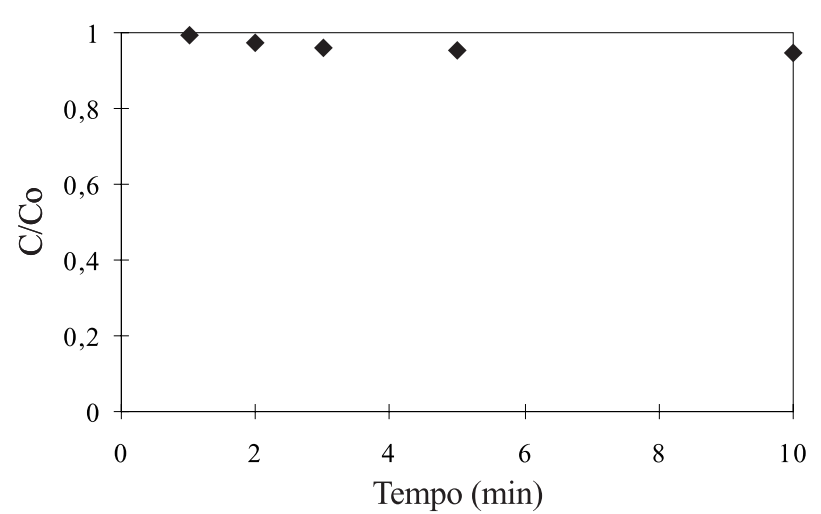

(a)

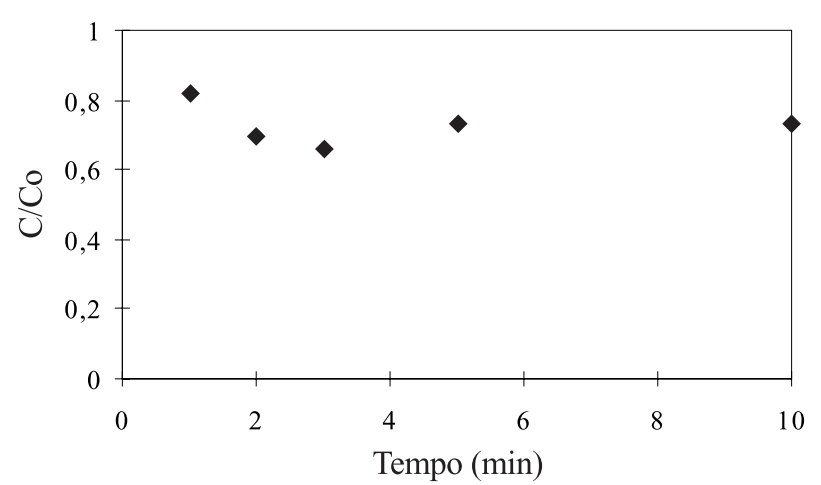

(b)

Figura 4. Comportamento cinético dos copolímeros de Sty-DVB sintetizados em presença de misturas $60 \%$ TOL/40\% DEHPA (a) e 50\% TOL $/ 50 \%$ (b) no sistema 3 (30\% de DVB, 200\% de diluição)

de DEHPA, que impede a difusão da solução aquosa de íons através da estrutura porosa (Figura 4).

Comparando-se os suportes preparados com 50\%TOL/50\%EHEHPA nos sistemas com 60\% de DVB e $100 \%$ de diluição (sistema 2 ) e com $30 \%$ de DVB e $200 \%$ de diluição (sistema 3) observa-se que ambos apresentaram a mesma capacidade, apesar da grande diferença do teor de EHEHPA que estes copolímeros apresentam. Porém, o suporte preparado no sistema 3 apresenta uma maior velocidade de retenção dos íons, o que se deve ao seu maior volume e maior diâmetro de poros (Figura 5).

Pode-se concluir, portanto, que o aumento da velocidade de retenção dos íons é função principalmente de sua morfologia, pois suportes com a mesma capacidade ou o mesmo teor de agente complexante podem apresentar velocidades diferentes de acordo com sua estrutura porosa.

$\mathrm{O}$ aumento da velocidade de retenção é função principalmente do diâmetro médio de poros, pois este determina a velocidade de difusão dos íons e a homogeneidade da distribuição do agente complexante sobre a superfície da matriz polimérica.

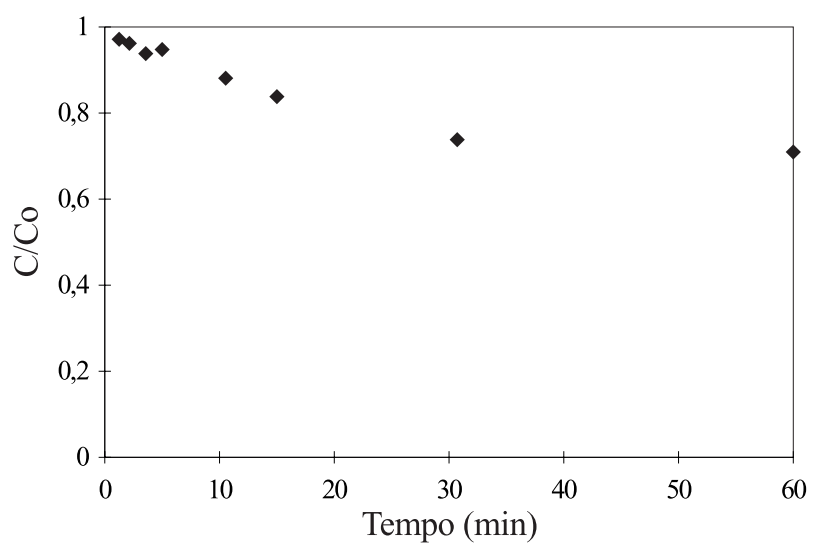

(a)

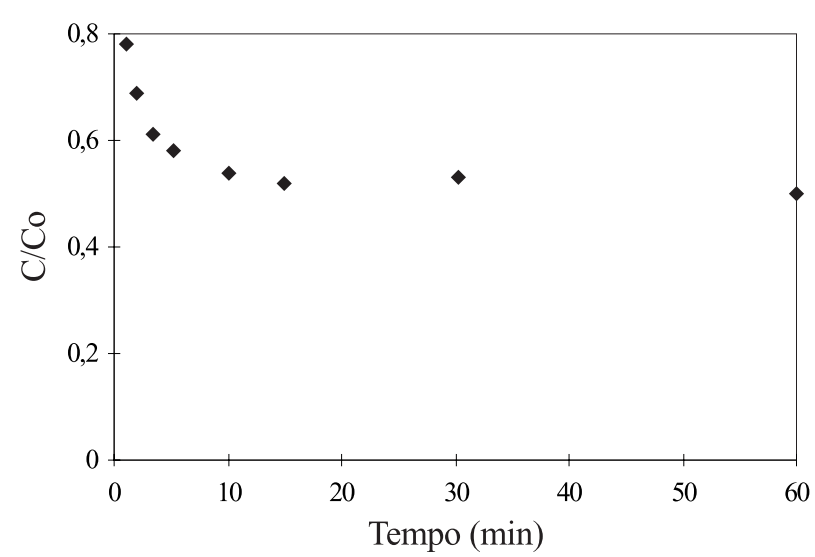

(b)

Figura 5. Comportamento cinético dos copolímeros de Sty-DVB sintetizados em presença de misturas 50\% tolueno/50\% EHEHPA nos sistemas (a) 2 (60\% DVB, 100\% diluição) e (b) 3 (30\% de DVB, 200\% de diluição)

\section{Conclusões}

O uso de EHEHPA ou DEHPA puros ou combinados com tolueno durante a copolimerização de estireno com divinilbenzeno possibilitou a obtenção de copolímeros com grande diversificação de estruturas porosas, desde gel até macroporosas em função da composição do sistema reacional. $\mathrm{O}$ aumento do grau de diluição provocou um maior efeito no aumento da porosidade dos copolímeros do que o aumento do teor de DVB. O aumento excessivo do diâmetro de poros com a utilização de altos teores de agente complexante nas misturas deu origem à formação de pérolas de copolímeros com altos diâmetros de poros tornando-as muito frágeis, além de prejudicar a distribuição homogênea do agente complexante na estrutura porosa. O aumento da capacidade e da cinética de complexação dos suportes foi função, principalmente, do diâmetro de 
poros dos copolímeros, sendo este o parâmetro responsável pela difusão dos íons através da matriz polimérica.

\section{Agradecimentos}

Os autores agradecem à Metacril, à Nitriflex S.A., ao IEN/CNEN, ao PADCT/CNPq e ao CNPq pelo apoio recebido.

\section{Referências Bibliográficas}

1. Gupta, G. K.; Krishanamurthy N. - International Materials Reviews, 37(5), 197 (1992).

2. Rabelo, D.; Coutinho F. M. B. - Eur. Polym. J.,30(6), 675 (1994).

3. Rabelo, D.; Coutinho, F. M. B. - Polym. Bull., 33,487 (1994).
4. Poinescu, I.C.; Vlad C.; Carpov A.; Ioanid A. Angew. Makromol. Chem., 156, 105 (1988).

5. Belfer, S.; Egozy, Y.; Korngold, E. - J. Appl. Polym. Sci., 29, 3825 (1984).

6. Kauczor, H. W., Meyer, A. - Hydrometallurgy, 3,65 (1978).

7. Barbosa, C.C.R.; "Síntese, caracterização e aplicação em extração cromatográfica de resinas à base de estireno e divinilbenzeno", Tese de Doutorado, Universidade Federal do Rio de Janeiro, Brasil, (1994).

8. Teixeira, V.G. - "Síntese e caracterização de copolímeros de estireno-divinilbenzeno para separação de terras raras", Tese de Mestrado, Universidade Federal do Rio de Janeiro, Brasil, (1997).

9. Rabelo, D.; Coutinho, F. M. B. - Polym. Bull., 33,493 (1994).

Recebido: 08/12/97

Aprovado: 07/07/98 